\title{
Anestesia y COVID-19
}

\author{
Anesthesia and COVID-19 \\ Jaime Pablo Antonio Ortega García, ${ }^{*}$ Lillian Jovana Herrera Parra ${ }^{\ddagger}$
}

Citar como: Ortega GJPA, Herrera PLJ. Anestesia y COVID-19. An Med ABC. 2021; 66 (3): 218-222. https://dx.doi.org/10.35366/101671

\section{RESUMEN}

A más de un año de la declaración de la pandemia COVID-19 por la Organización Mundial de la Salud, en nuestro país se han registrado hasta julio de 2021 más de 2.5 millones de casos y alrededor de 233 mil muertes. La principal transmisión del virus SARS-CoV-2 es por gotas y aerosoles provenientes del sistema respiratorio, de aquí deriva la relación y la suma importancia del papel del anestesiólogo en el manejo del paciente con enfermedad por COVID-19. Es bien conocido que el anestesiólogo es, por excelencia, de todas las especialidades de la medicina, el experto en vía aérea, debido a esto, durante el último año nuestra especialidad ha sido parte del manejo avanzado de ésta dentro y fuera de quirófano. Siendo la intubación orotraqueal catalogada como el procedimiento de más alto riesgo para la transmisión del virus, el anestesiólogo es considerado una parte fundamental del equipo de médicos encargados del manejo del paciente grave con enfermedad por COVID-19. En nuestro país, el impacto que tiene la falta de apego a protocolos de manejo de la vía aérea y falta de equipo de protección para el personal de primera línea es algo de suma importancia a considerar. En esta revisión se presta especial atención a los datos claves sobre el virus SARS-CoV-2, el impacto de la pandemia COVID-19 sobre la anestesiología como especialidad y sobre la educación y formación del anestesiólogo durante la pandemia.

Palabras clave: COVID-19, virus SARS-CoV-2, anestesia, vía aérea, educación médica.

\begin{abstract}
More than a year after the declaration of the COVID-19 pandemic by the World Health Organization, in our country until July 2021 more than 2.5 million cases have been registered. The main transmission of the SARS-CoV-2 virus is by drops and aerosols from the respiratory system, hence the relationship and the outmost importance of the role of the anesthesiologist in the management of the patient with COVID-19 disease derives. It is well known that the anesthesiologist is par excellence of all medical specialties the airway expert, due to this during the last year our specialty has been part of the advanced management of this inside and outside the operating room. As orotracheal intubation is classified as the highest risk procedure for the transmission of the virus, the anesthesiologist is considered a fundamental part of the team in charge of the management of critically ill patients with COVID-19 disease. In our country, the impact of lack of adherence to airway management protocols and lack of protective equipment for front-line personnel is something of utmost importance to consider. In this review, special attention is paid to key data on the SARS-CoV-2 virus, the impact of the COVID-19 pandemic on anesthesiology as a medical branch, and on the anesthesiologist education and training during the pandemic.
\end{abstract}

Keywords: COVID-19, SARS-CoV-2 virus, anesthesia, airway, medical education.

\footnotetext{
* Anestesiología / Medicina Crítica. Médico adscrito a Anestesiología, ABC. Profesor adjunto del Curso Postgrado de Anestesiología de la UNAM.
}

‡ Anestesiología. Médico Residente de Subespecialidad en Medicina Crítica.

Centro Médico American British Cowdray. México.
Recibido: 17/06/2021. Aceptado: 17/08/2021.

\section{Correspondencia:}

Lillian Jovana Herrera Parra

E-mail: lillianherrerap@gmail.com 
Abreviaturas:

ARN = Ácido ribonucleico

ASA = Sociedad Americana de Anestesiología

COVID-19 = Enfermedad por coronavirus 2019.

DAS = Sociedad de Vía Aérea Difícil.

EPP = Equipo de protección personal

OMS = Organización Mundial de la Salud .

RCP = Reanimación cardiopulmonar.

$\mathrm{UTI}=$ Unidad de Terapia Intensiva .

\section{INTRODUCCIÓN}

A finales del año 2019, inició la presentación de casos de neumonía severa atípica, provocados por un nuevo coronavirus, inicialmente llamado 2019-nCoV, en la zona metropolitana de Wuhan en China. La fecha de inicio de síntomas en el primer paciente identificado fue el primero de diciembre de 2019. ${ }^{1,2}$

El 29 de diciembre del mismo año cuatro casos fueron reportados, todos relacionados con el mercado de mariscos de Huanan y fueron catalogados como neumonía de causa desconocida. Después se identificó y nombró al virus como SARS-CoV-2, este es el tipo ARN de cadena simple, tiene una envoltura de glucoproteína que semeja una corona, de ésta destacan la proteína $\mathrm{E}, \mathrm{M}$ y especialmente la $\mathrm{S}$ (por spike en inglés), esta proteína es la encargada de interaccionar fuerte y específicamente con otra proteína localizada en la célula que infecta, ya en el organismo sólo las células que tienen el receptor adecuado capaz de interactuar con la espiga son susceptibles a ser infectadas y comenzar el ciclo de replicación viral. Los coronavirus son virus ARN que se dividen en cuatro géneros: alfa, beta, gamma y delta, causan enfermedades de leves a graves en humanos y animales. Existen siete coronavirus humanos, cuatro de ellos alfa y tres beta coronavirus, responsables de 5\% de enfermedades respiratorias y para los que el ser humano ha desarrollado significativamente anticuerpos, pero han aparecido de forma reciente otros tres beta coronavirus, SARS-CoV, MERS-CoV y SARSCoV-2, este último genera la enfermedad conocida como COVID-19, con un periodo de incubación de dos días a dos semanas. ${ }^{1,2} \mathrm{El}$ análisis del genoma de los SARS-CoV-2 ha identificado dos tipos principales, designados como tipo L y tipo S. El SARS-CoV-2 tipo $\mathrm{S}$ es ancestral y menos agresivo con $30 \%$ de prevalencia aproximadamente. El SARS-CoV-2 tipo L es una evolución del tipo S, es más agresivo y con mayor prevalencia, esto con el fin de mostrar la evolución que puede tener el virus y así como hay una variante L puede haber otras en el futuro. ${ }^{3}$

La emergencia internacional fue declarada el 30 de enero de 2020, posterior a esto, el 11 de febrero del mismo año la Organización Mundial de Salud (OMS) nombró a la enfermedad causada por el virus SARS-CoV-2 como COVID-19 y se dio a conocer su transmisión por contacto directo, superficies contaminadas de todo tipo, fluidos corporales y sobre todo por gotas y aerosoles.

El 11 de marzo de 2020 la OMS la declara pandemia. El primer caso o caso índice de COVID-19 en México se detectó el 27 de febrero de 2020 en la Ciudad de México, una persona que había viajado a Italia y tenía síntomas leves. ${ }^{4}$

En México, de los pacientes que dieron positivo a COVID-19, 70\% fue asintomático, 10\% con síntomas leves y un $20 \%$ con claros síntomas de la enfermedad; de este último porcentaje, un 5-6\% presentaron cuadros de gravedad y fueron manejados en las unidades de terapia intensiva, según información del Instituto Nacional de Salud Pública en su reporte de diciembre de 2020. Nuestro país ha sido especialmente devastado por la pandemia, las causas son diversas. Los casos confirmados en cifras oficiales rondan los tres millones de personas y los fallecimientos cercanos a los 300 mil, pero debido a la falta de registro e identificación, seguro son mucho más elevados. Son muy pocas pruebas las que se hacen en nuestro país sin ellas, es prácticamente imposible emitir una tasa de mortalidad creíble, según los datos cotidianos de la Secretaría de Salud la mortalidad es muy superior en los hospitales públicos con respecto a los privados, aunque habría que analizar muchas causas a su alrededor.

\section{Importancia del anestesiólogo en el manejo de COVID-19}

Como se mencionó antes, la principal forma de transmisión del virus es el aparato respiratorio que emite gotas de tamaño entre 5-10 micrómetros, éstas caen fácilmente al suelo, las gotas más pequeñas menores a 5 micrómetros son líquidas, flotan en el aire, incluso por horas y son emitidas al toser, estornudar, hablar o sólo respirar y es lo que conocemos como aerosoles. El contenido de agua se evapora y se vuelve más pequeña, más tiempo permanecerá suspendida en el aire..$^{5,6}$

Pocas especialidades en medicina están tan expuestas a la vía aérea como los anestesiólogos. Los momentos de mayor contacto son la intubación, extubación, manejo vía aérea quirúrgica de emergencia y RCP. Debido a lo anterior, dichos procedimientos son manejados con técnicas ampliamente descritas por autoridades sanitarias como la OMS, así como 
las de cada país y por asociaciones médicas como la Sociedad Americana de Anestesiología (ASA por sus siglas en inglés) y la Sociedad de Vía Aérea Difícil (DAS por sus siglas en inglés), pero el común denominador y punto crítico de estos nuevos protocolos es el equipo de protección personal, seguido por las técnicas recomendadas para su manejo.

Los anestesiólogos se han desempeñado eficazmente, en áreas ajenas al perioperatorio, como es el caso de las UTI, en las que han adoptado papeles de intensivista, terapista respiratorio, manejo de accesos vasculares, gestor de vías aéreas, ventilación mecánica, etcétera; también han participado en las salas de urgencias y áreas de hospitalización en general, incluyendo servicios paraclínicos. Durante las faces más álgidas de la enfermedad, se han presentado situaciones cambiantes de manera continua que han generado trastornos en la comunicación, confusión y ansiedad, siendo actores de una atención por momentos caótica, en la que su propia vida está en riesgo.

En anestesiología como en cualquier otro servicio médico, se requiere de una estructura (personal, equipo, fármacos y educación) y un proceso (políticas, protocolos y procedimientos) que cuando se integran dan lugar a un sistema (programas, organizaciones y cultura), todo esto repercutirá en la evolución del paciente que se basa en seguridad, calidad y satisfacción. ${ }^{7}$

Dado que el COVID-19 es una enfermedad nueva que puede llegar a ser mortal, afecta seriamente el estado emocional del anestesiólogo, así como sus habilidades técnicas, razonamiento y su conocimiento dando lugar a un estado de estrés al manejar a estos pacientes, el estrés es alto en condiciones normales para un anestesiólogo y es habitual un estado de agotamiento conocido como burnout, muchos trabajos han estudiado estas condiciones y la manera de manejarlos. ${ }^{8}$

En cuanto al ámbito quirúrgico y COVID-19, los pacientes que son sometidos a cirugía electiva tienen malas evoluciones hasta en $44 \%$, pueden requerir UTI y presentar hasta $20 \%$ de mortalidad, principalmente por complicaciones pulmonares sin limitarse sólo a ellas, en conclusión, es muy mala combinación cirugía con COVID-19, malas evoluciones y mortalidad muy alta, por lo que cirugías electivas deben diferirse. El único procedimiento electivo al cual se someten los pacientes infectados es la traqueotomía, la cual ofrece grandes ventajas si se realiza en el tiempo apropiado, que se calcula entre 14-21 días de intubación. ${ }^{9}$
Es necesario estudiar y especificar cuándo y de qué manera se omiten procedimientos programados, a fin de concentrarnos en una calamidad mayor y cuáles son los lineamientos para reiniciarlos, así como establecer lo más rápido posible cuál es la mejor manera de estudiar pacientes que tengan que llegar a sala de operaciones para evitar complicaciones, independientemente de la causa de origen.

\section{Medidas de protección para el médico anestesiólogo}

Según el reporte de la Confederación Latinoamericana de Sociedades de Anestesiología (CLASA) del año 2020, siendo la anestesiología una especialidad de alto riesgo para exposición a esta enfermedad, en México se reportaron 350 colegas infectados de marzo a diciembre del año 2020, de éstos fallecieron 80 médicos, representando $23 \%$ de mortalidad, por lo que nuestro país es el que más fallecimientos por COVID-19 tuvo en esta especialidad entre todos los que participaron en el estudio, lo cual evidencia nuestro débil sistema sanitario y la falta de políticas adecuadas para enfrentar la pandemia.

El equipo de protección personal o individual (EPP) es la mejor forma de proteger al personal. Están descritos varios niveles de protección, de acuerdo con el grado de exposición, el nivel más alto es el 3 o 4 según las autoridades sanitarias de cada país, asociaciones médicas, OMS y otras agrupaciones, por ejemplo, la OMS da cuatro niveles de protección, el nivel 1 sólo se refiere al lavado de manos, distancia y el uso de cubre boca-nariz y el nivel 4 incluye lavado de manos, técnica especial para no contaminar la colocación del equipo, que abarca bata desechable, mascarilla N95 o equivalente, gafas ajustables herméticamente, en su caso protectores oculares con componente lateral con sistema antiempañante, doble guante, gorro especial protector y careta protectora, también el retiro de este equipo requiere de técnica para evitar contaminación. Vale la pena mencionar que los equipos de máxima protección pueden presentar overoles que incluyen, botas, escafandra, purificadores de aire y sistema antiempañante que aíslan al proveedor 360 grados. Se han propuesto dispositivos de barrera, un ejemplo son las cajas de acrílico, pero su uso se encuentra en debate y de ninguna manera sustituyen el EPP. ${ }^{10}$

El cuidado, lavado, esterilización y sobre todo los filtros de la máquina de anestesia se resumen en trabajos ya publicados. ${ }^{9}$ Se han estudiado los purificadores de aire y su uso en sala de operaciones, el intercambio de aire debe contar con una fluidez mínima 
de intercambio que permita eliminar 99\% de patógenos en 18 minutos, así como las salas con presiones negativas en pacientes sospechosos o confirmados. ${ }^{9}$

\section{Educación médica y formación del anestesiólogo durante la pandemia por COVID-19}

Esta enfermedad también ha impactado el mundo de la educación médica y en este sentido no volverá a ser el mismo, se deben buscar soluciones innovadoras en este campo. No se debe esperar el regreso a la normalidad, sino optimizar el aprendizaje en línea, con sesiones virtuales interactivas, teleconferencias o videoconferencias, sistemas innovadores de evaluación que sin duda tendrán ventajas pero también debilidades. ${ }^{11}$

Todas estas medidas de aprendizaje contribuyen a que las instituciones organicen programas y generen conocimiento día a día sobre el virus. El curso clínico y pronóstico de los pacientes se basa en seguridad, calidad y satisfacción, pero se ve mermado porque existen muchos componentes en los eslabones del sistema de atención, que distan mucho de ser ideales por falta de evidencia, conocimientos científicos o limitantes como la economía. Sólo el tiempo, estudio, evidencia y recursos lograrán mejorar nuestro cometido.

Algunos puntos relevantes hasta el momento en nuestra rama médica en el manejo de este tipo de pacientes podrían incluir, sin pretender abarcar todo, que se trata de una enfermedad infecciosa, fácilmente contagiosa, en especial a través de la vía aérea del paciente y puede llegar a ser letal, sobre todo para el personal de edad avanzada y con comorbilidades, las pruebas para detectar pacientes son caras y no son completamente confiables; aun en protocolos que combinan estudios, difícilmente en algún otro escenario los especialistas en anestesia han estado sometidos a tan elevados niveles de estrés, fatiga y confusión, incluyendo el temor a perder la vida, por lo que es de capital importancia el equipo de protección personal. Falta definir aspectos como cuáles son los más apropiados y estandarizarlos, qué componentes pueden esterilizarse y ser reutilizados, ${ }^{12}$ se ha presentado escasez de EPP sobre todo en los picos más pronunciados de la pandemia y en los casos de recursos limitados. ${ }^{13}$ Es de gran relieve el cuidado, preparación, limpieza y aplicación de filtros en las máquinas de anestesia, así como las características que deben tener las salas de operaciones y áreas del perioperatorio (recambio de aire efectivo, presiones negativas, equipo de limpieza etcétera). Queda cla- ro que los momentos más delicados de exposición para el anestesiólogo son la intubación, ventilación y extubación; existen protocolos para el manejo de estos procedimientos específicamente por parte de las principales asociaciones y autoridades sanitarias, tanto de cada país como en el ámbito mundial. ${ }^{14-16}$ En las etapas agudas, prácticamente se han anulado las cirugías programadas para evitar más contagios y dar prioridad a este padecimiento, a partir del inicio de esta pandemia prácticamente quedó cancelada la educación médica presencial, hay alternativas, pero lamentablemente para los anestesiólogos, sobre todo los que están en formación, muchos procedimientos, destrezas y conocimientos de esta especialidad exigen la educación presencial.

\section{CONCLUSIONES}

Es fundamental contar con programas completos y agresivos de apoyo a los anestesiólogos, no sólo en la parte cognitiva y habilidades técnicas, también es prioritario el aspecto psicológico y emocional, así como disponer de equipos de protección personal que confieran seguridad según el agente del que se trate. Es conveniente que las autoridades sanitarias se acerquen a mecanismos para evitar escases de EPP. Los anestesiólogos deben estar plenamente apoyados desde el punto de vista profesional, pero sobre todo legalmente para ejercer funciones fuera del escenario donde normalmente se desempeña (UTI, salas de urgencias, imagenología, hospitalización, etcétera). ${ }^{17}$ La pandemia por COVID-19 ha presentado retos sin precedentes para los departamentos de anestesiología, se deben establecer procesos para activar equipos de trabajo y hacer frente a escenarios de crisis como la que nos ocupa, privilegiar, organizar, centralizar y clarificar la comunicación es esencial, formar lideres especializados en situaciones de crisis generadas por agentes de muy diverso origen, es decir, tenemos que dar mayor importancia y prepararnos mejor para situaciones de este tipo que antes merecían poca atención.

Los esfuerzos académicos deben continuar de la manera que tengamos a la mano, revolucionar métodos en la transmisión del conocimiento en línea, plataformas académicas, teleconferencias, videoclases y todo lo que aplique en la enseñanza-aprendizaje a distancia y la presencial que pudiera utilizarse. ${ }^{17}$

La aparición de vacunas cambió por completo el escenario, por lo menos disminuyó notablemente el estrés generado por la enfermedad, y a mediano y largo plazo habrá un decremento en la presentación de 
casos para lograr hacer de este padecimiento algo manejable. En un alarde de recursos humanos, económicos y tecnológicos, se lograron sacar vacunas, incluidas las de nueva tecnología (ARNm), en tiempo récord, como el caso de Pfizer que se logró en 10 meses, cuando normalmente se necesitaban 10 años. Falta mucho estudio en su seguridad y eficacia, pero el objetivo principal se ha conseguido hasta el momento.

De acuerdo con lo que hemos vivido a lo largo de esta pandemia, es quizá momento de hacer algunas reflexiones, como el estar conscientes y relativamente preparados para situaciones similares que en un futuro se pudieran presentar, que incluyen no sólo enfermedades infecciosas, sino de diversa naturaleza, identificar qué tipo de agentes pudieran dar lugar a eventos como éste a fin de conocerlos mejor que pudieran ser de tipo infeccioso, físico, químico, climático etcétera, así como ejercer lineamientos generales de atención que nos permitan desarrollar en corto tiempo protocolos específicos para el médico anestesiólogo.

\section{REFERENCIAS}

1. The 2019-nCoV Outbreak Joint Field Epidemiology Investigation Team, Li Q. Notes from the field: an outbreak of NCIP (2019-nCoV) infection in China-Wuhan, Hubei province, 2019-2020. China CDC Weekly. 2020; 2 (5): 79-80.

2. Tan WJ, Zhao X, Ma XJ. A novel coronavirus genome identified in a cluster of pneumonia cases. Wuhan, China 2019-2020. China CDC Weekly. 2020; 2 (4): 61-62.

3. Tang X, Wu C, Li X, Song Y, Yao X, Wu X et al. On the origin and continuing evolution of SARS-CoV-2. Natl Sci Rev. 2020; 7 (6): 1012-1023.

4. Suárez V, Suarez Quezada M, Oros Ruiz S, Ronquillo De Jesús E. Epidemiología de COVID-19 en México: del 27 de febrero al 30 de abril de 2020. Rev Clin Esp (Barc). 2020; 220 (8): 463-471.

5. Gralton J, Tovey E, McLaws ML, Rawlinson WD. The role of particle size in aerosolised pathogen transmission: a review. J Infect. 2011; 62 (1): 1-13.
6. Garner JS. Guideline for isolation precautions in hospitals. The Hospital Infection Control Practices Advisory Committee. Infect Control Hosp Epidemiol. 1996; 17 (1): 53-80.

7. John-Nwankwo J. ACLS provider manual: study guide for ACLS with EKG interpretations. Independently Published; 2019.

8. Chen Q, Liang M, Li Y, Guo J, Fei D, Wang L et al. Mental health care for medical staff in China during the COVID-19 outbreak. Lancet Psychiatry. 2020; 7 (4): e15-e16.

9. COVID-19 and anesthesia FAQ - anesthesia patient safety foundation [Internet]. Apsf.org. 2020 [citado el 29 de junio de 2021]. Disponible en: https://www.apsf.org/covid-19-andanesthesia-faq/

10. Servín TE, Nava LH, Romero GAT, Sánchez GFJ, Huerta GG. Equipo de protección personal y COVID-19. Cir Gen. 2020; 42 (2): 116-123.

11. Martinelli SM, Chen F, Isaak RS, Huffmyer JL, Neves SE, Mitchell JD. Educating anesthesiologists during the coronavirus disease 2019 pandemic and beyond. Anesth Analg. 2021; 132 (3): 585-593.

12. Meng L, Qiu H, Wan L, Ai Y, Xue Z, Guo Q et al. Intubation and ventilation amid the COVID-19 outbreak: Wuhan's experience. Anesthesiology. 2020; 132 (6): 1317-1332.

13. Newman M. Covid-19: doctors' leaders warn that staff could quit and may die over lack of protective equipment. BMJ. 2020; 368: $\mathrm{m} 1257$.

14. Sorbello M, El-Boghdadly K, Di Giacinto I, Cataldo R, Esposito C, Falcetta S et al. The Italian coronavirus disease 2019 outbreak: recommendations from clinical practice. Anaesthesia. 2020; 75 (6): 724-732.

15. Brewster DJ, Groombridge CJ, Gatward JJ. Consensus statement: Safe Airway Society principles of airway management and tracheal intubation specific to the COVID-19 adult patient group. Med J Aust. 2021; 214 (1): 46-46.e1.

16. Cook TM, El-Boghdadly K, McGuire B, McNarry AF, Patel A, Higgs A. Consensus guidelines for managing the airway in patients with COVID-19: Guidelines from the Difficult Airway Society, the Association of Anaesthetists the Intensive Care Society, the Faculty of Intensive Care Medicine and the Royal College of Anaesthetists. Anaesthesia. 2020; 75 (6): 785-799.

17. Meng L, McDonagh DL. Impact of coronavirus and COVID-19 on present and future anesthesiology practices. Front Med (Lausanne). 2020; 7: 452. 